\title{
Smart Garbage Bin - A Waste Management System
}

\author{
Nayan Patel, Omkar Mugdum, Tirthesh S. Pawar, Deepshikha Chaturvedi, Shashikant S. Radke \\ Department of Computer Engineering \\ Shah and Anchor Kutchhi Engineering College, Chembur \\ Mumbai, India \\ Nayan.patel@sakec.ac.in, Omkar.mugdum@sakec.ac.in, pawartirthesh2@gmail.com, deepshikha.chaturvedi@sakec.ac.in, \\ Shashikant.radke@Sakec.ac.in
}

\begin{abstract}
In today's era it is very important to manage and handle the waste. The waste bins kept in the public places overflows before the garbage cleaners arrive to collect the waste. As a result, the bins are not cleared off on timely basis and foul smell, maintaining of hygiene, spread of disease are the biggest problems in the public area. Smart Dustbin is the need of the hour for the urban areas. The paper aims at the development of a smart garbage bin alert system. The complete IoT based dustbin is designed and developed to automate the process and monitor it efficiently. The system measures the level of waste inside the bin and auto locks the garbage bin and informs municipal authorities about the same stating the location of the bin so that corrective measure can be taken for timely collection of garbage and avoidance of the filthiness in the area. The system will also adapt with network environment to manage all information from waste management.
\end{abstract}

Keywords— waste management, garbage bins, garbage alert system, IOT, smart cities, Arduino.

\section{INTRODUCTION}

The devices are connected to each other in a network and communicate and transfer data with the help of Internet of Things. The main aim of IoT is to automate human life. The Internet of things is interconnection of the devices with sensors having network connectivity that enable these objects to gather and exchange data [1]. Garbage bin cleaning is the biggest challenge and the bins need to be cleaned regularly for keeping the surrounding clean. The main issue is monitoring the garbage level and taking the action accordingly. Thus, to reduce the human efforts, we have proposed "A Smart Garbage Bin". In this project we are aiming to implement a smart alert system for garbage clearance by giving an alert message to the municipal web server for instant cleaning of dustbin with proper verification supported level of garbage filling. The dustbin will be provided with a sensor which will help in tracking the level of the garbage bin so that it is easy to identify that the garbage bin is full. When the level of the bin reaches the threshold limit, the device will transmit the readings. These details can be reviewed by the concerned authorities from their desks with the help of Internet and front end technologies and an immediate action plan can be made to clean the dustbin/dustbins of a particular locality. [3]. Our most unique features of our project are RFID modules is installed to overcome the problem of unlocking the bin when the bin is fully-filled. Together our system is well connected with all the sensor and efficient to control the problem of waste management.

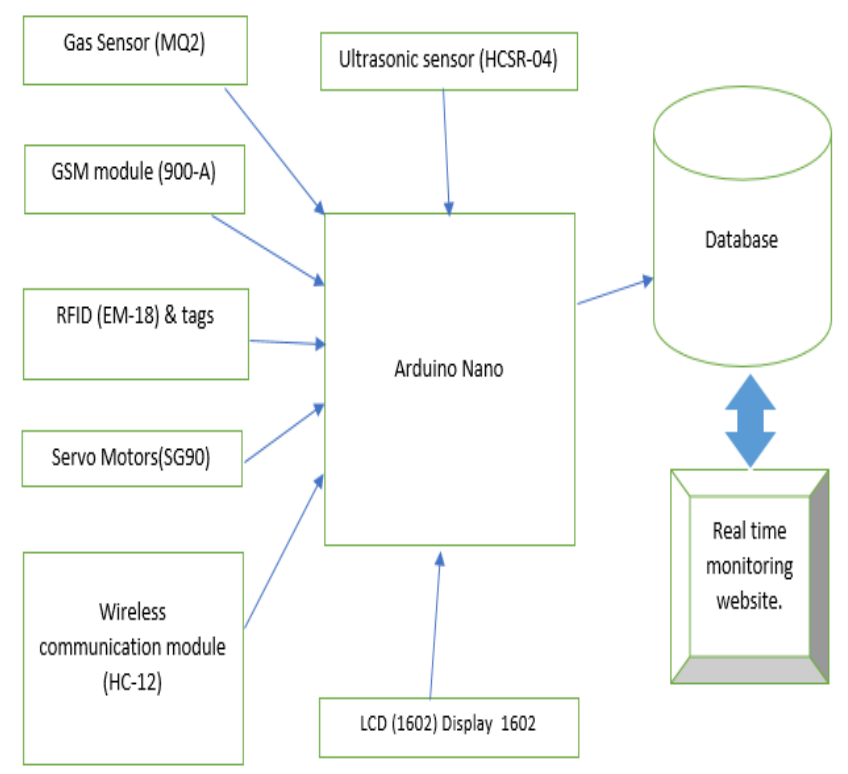

Figure 1: Basic Block diagram of system

\section{EXISITING SYSTEMS}

The problem regarding waste management in developing countries begins at the base level of waste management systems. Due to lack of waste management systems for disposal and collections, wastes and garbage ends up on the roads and surrounding area becomes dirty and unhealthy for a living. Instead of using plenty of bins in an unordered fashion around the city, we can have minimal number of smart bins that can be placed following a set defined alert protocol within the management system. As we have seen all around us, the dustbins get overflowed by waste and concerned municipal authorities usually don't get alerted within necessary time. Rohit, G. S., Chandra, M. B., Saha., S., \& Das purposed Smart Dual Dustbin Model for Waste Management in Smart Cities [2] consists of double dustbins, 


\section{ISSN NO: 2350-1146 I.F-5.11}

where second Dustbin B cannot be used until and unless Dustbin A is fully filled. Dustbin B can only be used once Dustbin A is full and then Dustbin A will not open until the waste is cleared in the bin A and contains features like whenever dustbin a is full it sends message to server. automatic open/close feature time delay for open/close. dustbin a can be used but dustbin b cannot be used until dustbin a is full. dustbin a will not open until reported waste is cleaned from it. Singhvi, R. K., Lohar, R. L., Kumar, A., Sharma, R., Sharma, L. D., \& Saraswat, R. K. (2019) purposed IoT Based Smart Waste Management System: India prospective [4] contains an IoT based technique and GSM/GPRS technique for interfacing between transmitter and receiver. It measures the percent filling of the dustbin and level of toxicity. It sends data to website so it can be seen in future implementing a system based on IOT that can send a message to corporation about overflow and toxicity level of dustbins. website to supervise data related to dustbins. message sent using GSM module. dustbin data updated on website Arduino to interface between GSM/GPRS module with sensors. Ultrasonic sensor and gas sensor. sometimes waste is thrown outside the dustbin when not monitored when dustbin gets full message should be sent to the machine who is responsible to clean dustbin data is stored for future use. ultrasonic sensor senses the distance less than $10 \mathrm{~cm}$ or gas sensor detects high level of toxicity then it sends SMS on mobile etc. [4]. Tripathi, A., Pandey, C., Narwal, A., \& Negi, D. (2018) purposed Cloud Based Smart Dustbin System for Metro Station [3] They have presented a viable solution for dustbins at metro stations, Ultrasonic sensor, geared motors, servo motors, Arduino NANO, raspberry-pi and solar panel for power supply. Contains features cloud based monitoring system for garbage monitoring with the use of cloud based monitoring there is no need of routine checkup of dustbin.to make system ecofriendly and preserve carbon neural footprint of metro we are using solar panel for power supply .metro uses RFID based tickets and smart cards.no need to create new RFID tags for the purpose of using bins .users with metro smart cards can easily access these bins[3].

Table 1: Comparison table of existing system

\begin{tabular}{|l|l|l|l|l|l|l|}
\hline S. & $\begin{array}{l}\text { Name of } \\
\text { the } \\
\text { oxisting } \\
\text { system. }\end{array}$ & $\begin{array}{l}\text { Autho } \\
\text { name. }\end{array}$ & $\begin{array}{l}\text { Lev } \\
\text { el } \\
\text { sens } \\
\text { or. }\end{array}$ & $\begin{array}{l}\text { Toxi } \\
\text { city } \\
\text { senso } \\
\text { r. }\end{array}$ & $\begin{array}{l}\text { Web/ } \\
\text { app } \\
\text { Supp } \\
\text { ort. }\end{array}$ & $\begin{array}{l}\text { RFID } \\
\text { for } \\
\text { overflo } \\
\text { w } \\
\text { protect } \\
\text { ion. }\end{array}$ \\
\hline 1. & $\begin{array}{l}\text { IoT } \\
\text { based } \\
\text { waste } \\
\text { manage } \\
\text { ment: } \\
\text { An } \\
\text { applicati } \\
\text { on to }\end{array}$ & $\begin{array}{l}\text { Malap } \\
\text { urti et } \\
\text { al. }\end{array}$ & true & false & false & false \\
\hline
\end{tabular}

Volume VI Issue III

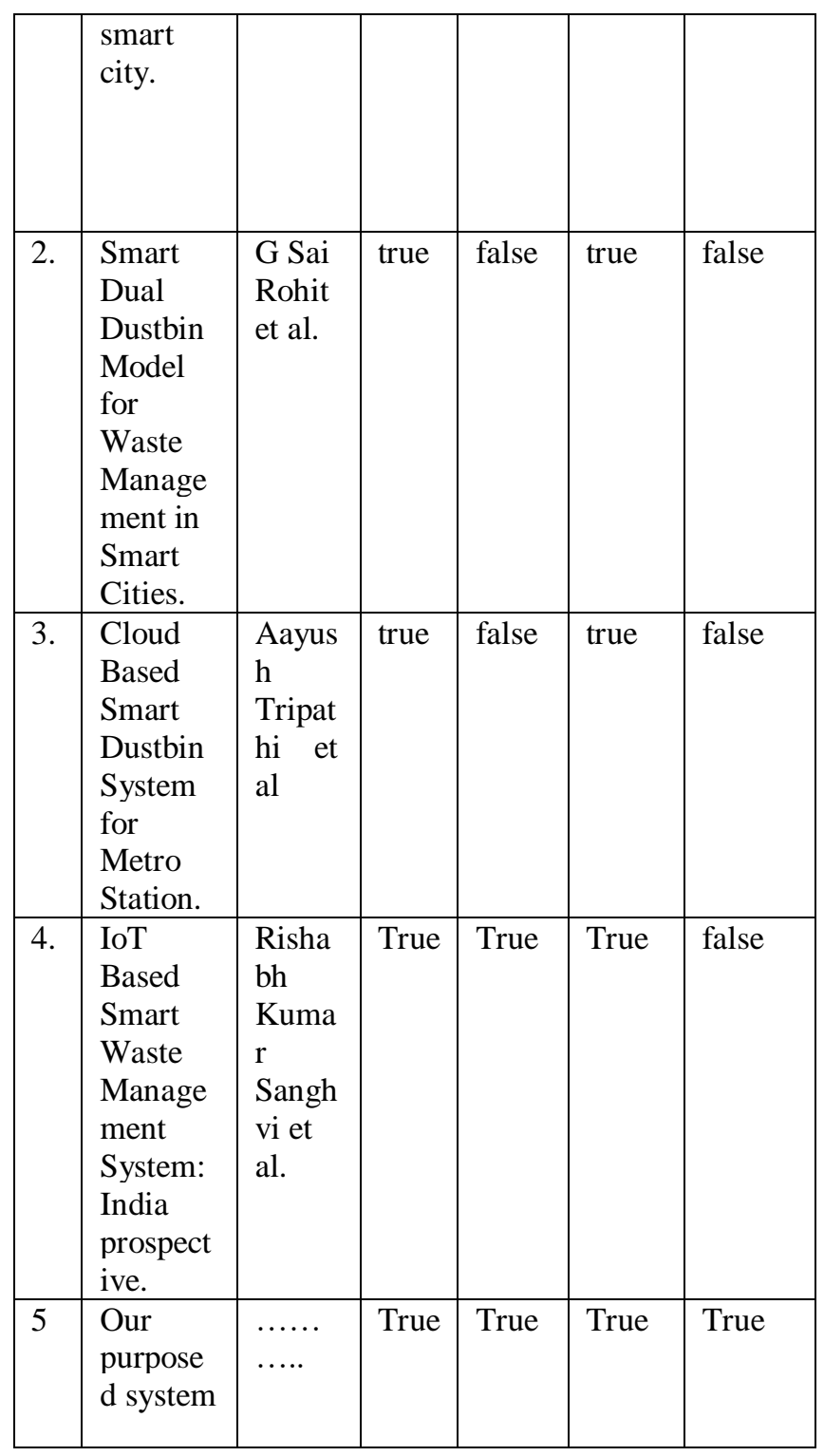

\section{LIMITATION IN EXISTING SYSTEM}

In our study of the existing Systems we found out the one major flaw in all the previous created systems. The flaw lies within the bin where once the bin is full and the bin is closed then after there is no way to open it or lock it properly. so, we created a RFID based solution to open and lock the bin. we have done it by attaching the RFID reader module to the system which will act as the receiver and authority people will have RFID tags to open the fully filled locked bin and our bin will automatically close the lid and lock it until valid RFID tag is not passed and open the lid of another backup bin. This feature will also prevent the spill of garbage on the roads when the garbage bin is full.

\section{IV.PROPOSED SYSTEM}


ISSN NO: 2350-1146 I.F-5.11

The system purposed in this paper is explained in following modules as Main module, User sensing module, Level sensing module, Gas sensing module, RFID module, Communication module.

A) Main module: - Our system core part is Arduino nano board. Our main aim for using Arduino nano was to decrease the cost of the overall system and make it less power consuming.

B) User sensing module: - This module consists of sensor known as ultrasonic sensor (HC-SR04). this Sensor used ultra-sonic pulses to detect the range from any object. We have used this sensor to detect the presence of any person standing outside the bin. if sensor detect any person within the 1meter range of dustbin it will automatically open the bin lid with the help of servo motors

C) Level Sensing module: - This module consists of sensor known as ultrasonic sensor (HC-SR04). this Sensor used ultra-sonic pulses to detect the range from any object. We have used to detect the level of garbage present inside the bin.

D) Gas sensing module: - This module consists of sensor known as MQ2 mainly used for detection of methane gas inside out bin because methane is a highly inflammable gas which can cause fire inside the system and damage the system.

E) RFID module: - This module contains RFID receivers and Tags. our main aim is to provide the lock mechanism to the full dilled bin.it contains one reader module and RFID tags whenever tags are in contact with reader module it performs the unlocking operation to the fully filled bin. Authority people will have those tags to open up the full filled bins. Through this we ensure the problem of overfilling the bin is solved.

F) Communication Module: - This Module has 2 parts first is bin to server communication \& second is bin to bin communication.

Bin to server communication: our nano board has compatibility for GSM(Global system for mobile).we have used GSM 900-A sensor this will collect all the Realtime data from the sensor and send alerts to registered authority mobile number and update the status of all the bins in our centralized database and through databases we sill update it to our websites.

Bin to Bin communication: for intercommunication we have used the hardware known as HC-12 communication module. It works on the principles of bluetooth.in our system this will provide a link between our main bin (BIN A) and our backup bin
Volume VI Issue III

(BIN B) for intercommunication and transfer of message between both the bins.

Working of our System:

Step 1: BIN A and BIN B require an external power supply(12v) to power on.

Step 2: Bin A starts by showing a message "Smart Garbage System" in the display module. BIN A starts by initializing a GPS module for communication and shows a message. Bin B also starts at the same time along with bin A with the same messages. The connection to the server starts through the Arduino module.

All components become active after this phase.

Step 3: Bin A and bin B update the current status to the server BIN B is locked and the message is displayed "Bin not in use" this bin is for future use. Bin A now displays the messages "Bin in use"

- Bin A is now activated and performs all the functions.

- Sensing the level and display it on the screen along with its percentage of filled garbage in the bin.

- Sensing the toxicity level and displaying it on the screen.

- Sensing the user presences and display the appropriate messages like if the user is present display the "opening the door" and if users move away displaying the "closing the doors".

- if the bin is full i.e. bin level is $100 \%$ then the message is displayed "Bin is full".

And we update the server and sends the message to concerned authority through the gsm module. All the parameter is updated on web and message is shown while updating to the server. Bin A is locked now.

Step 4: To open bin A RFID tag is used. Once valid tag is near RFID receiver locked i.e. (fully filled bin is opened). And the message is shown in the display. If the invalid tag is detected the invalid id message is displayed. And the current status of the bin is updated on the web.

Step 5: once bin A is fully filled. Bin B comes into action and bin B open ups by locking the bin A And all the same, functions that are done by Bin A will be carried out by Bin B $\&$ vice versa. This inter communication is done via Bluetooth.

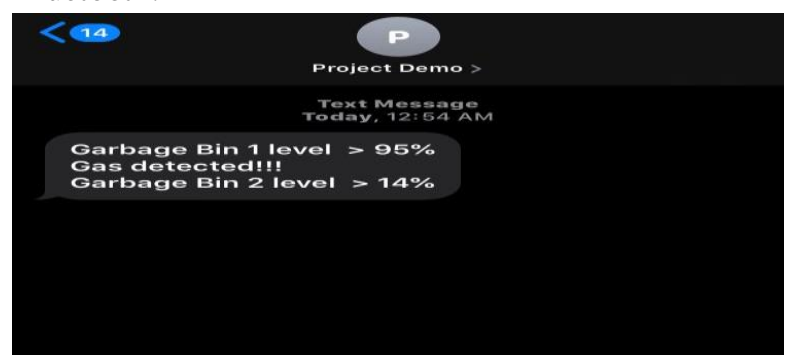

Figure 2: Screeshot of message sent 


\section{ISSN NO: 2350-1146 I.F-5.11}

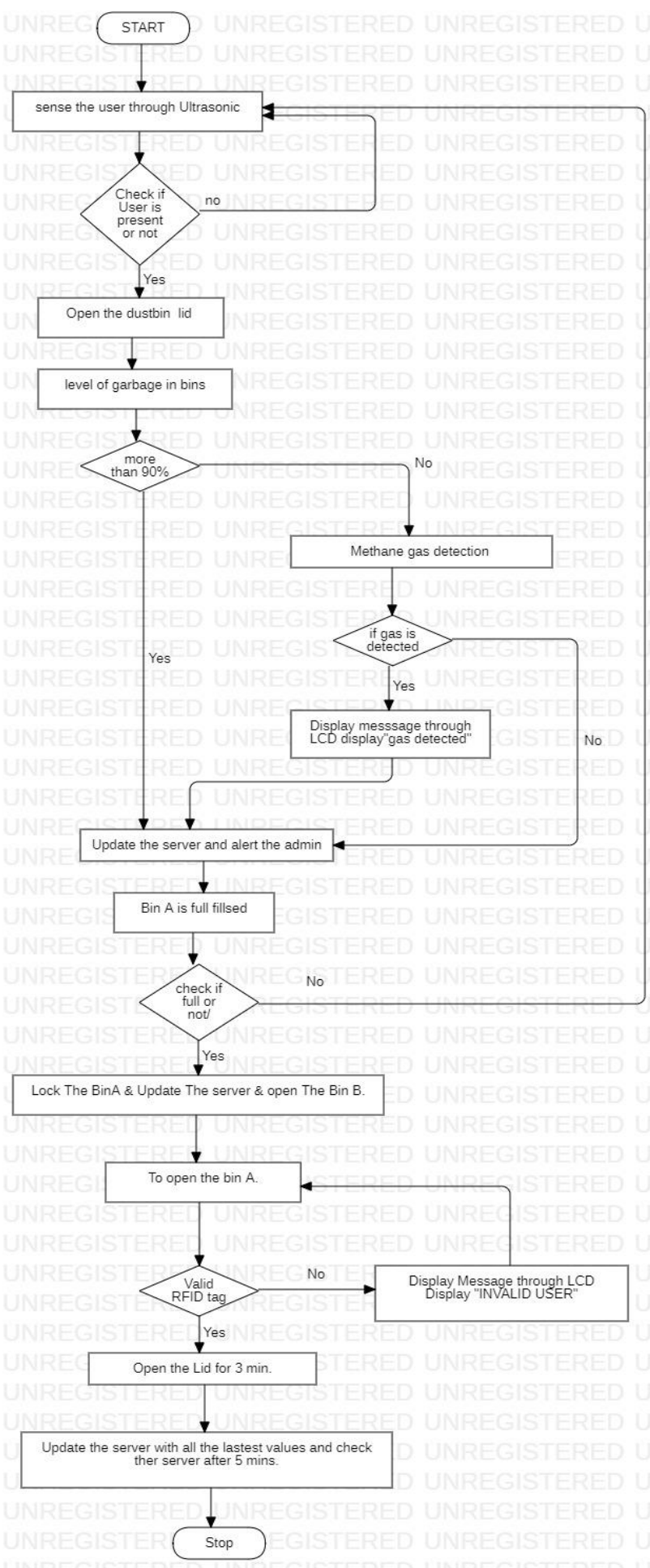

Figure 3: Flowchart diagram of our system

\section{V.RESULTS}

Ardunio nano and GSM module are connected thorugh wires and all the connections are done properly for both the bins and all the things are working fine.GSM moudle upadtes the server ate regular intervals and sending messages to concerened authorityAll the coding is done in aurdino IDE the peogram is runned on windows 7 system with processor of $3.0 \mathrm{GHz}$ with $16 \mathrm{~Gb}$ of memory.We have done proper testing to all the modules and we have observed all the modules are working fine with expected output with the small delay.

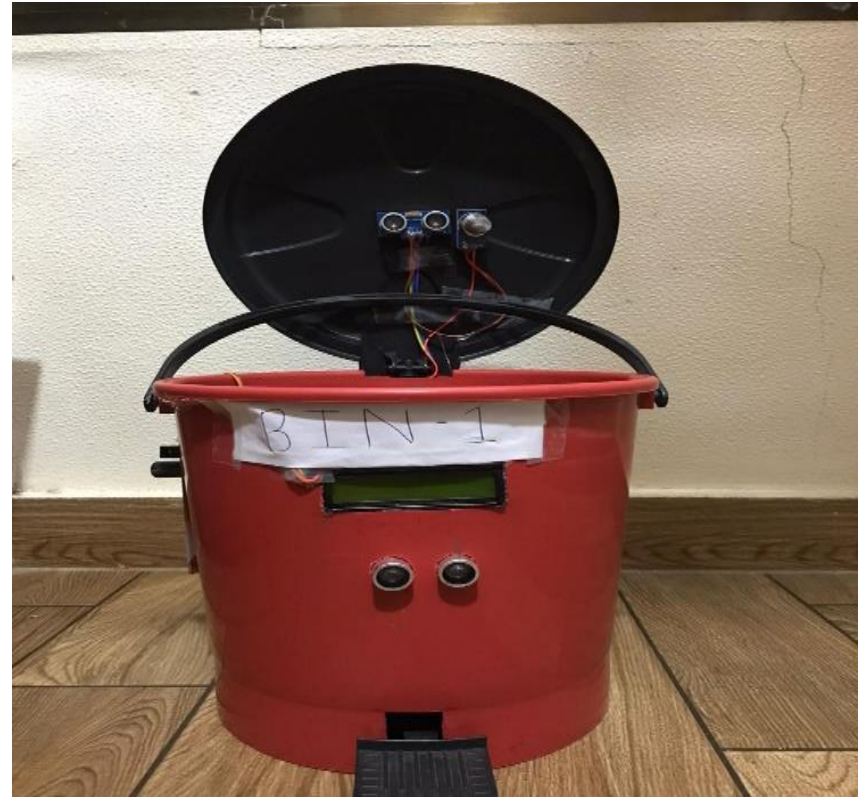

Figure 3: protoytpe Bin A.

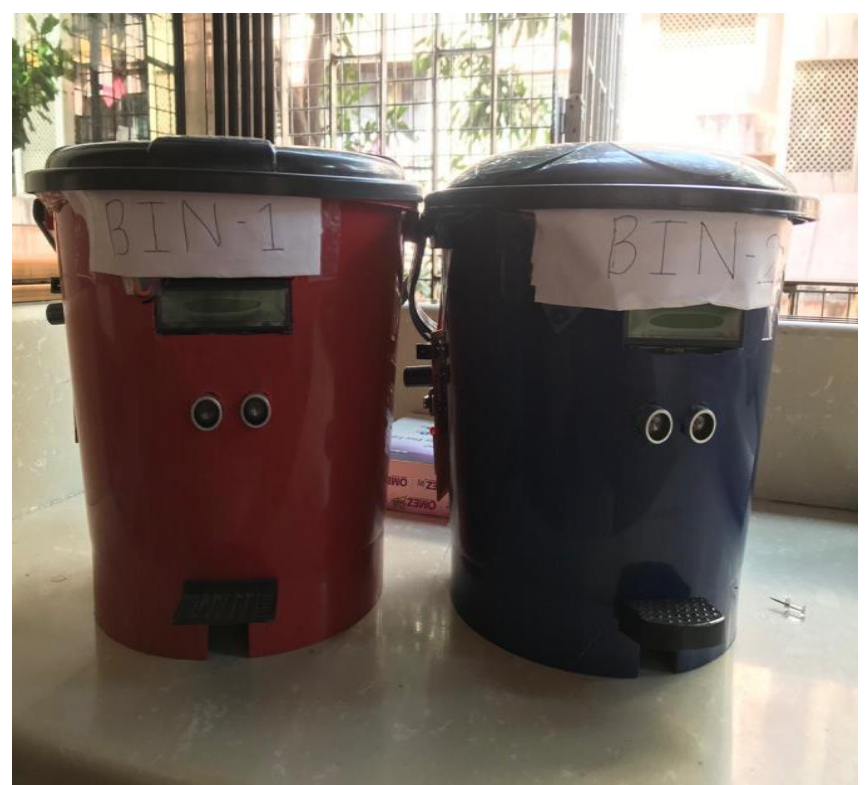

Figure 4: protoytpe Bin A and Bin B.

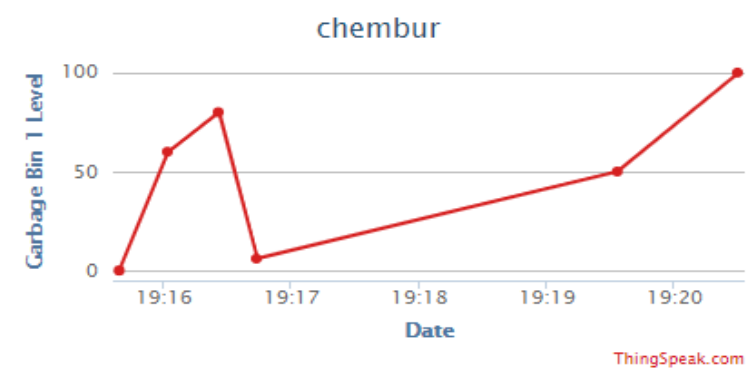

Figure 5: Bin A filled level. 


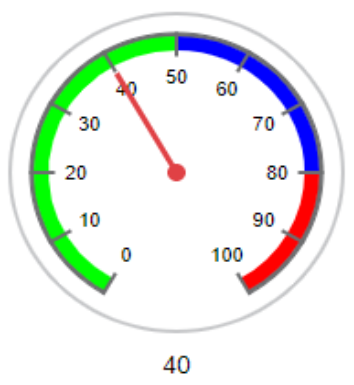

Figure 6: Realtime montioing of bin level.

\section{CONCLUSION}

In the upcoming years waste management is going to be the most critical issue for our future generations. Our system will help the future generations to Obtain and maintain the effective and efficient waste management. As city grows wastage management will gain top priority. Our System solves the most critical issue of the waste management i.e. overflowing of bins. Our system will also help authorities to have a track and keep record of each and every user which would help them to monitor the cleanliness in the city. Our main aim is to support the vision of our respected prime minister "Shri. Narendra Damodardas Modi" \& his initiative "Swachh Bharat Abhiyan". Our system has been tested and verified properly to make sure all the different parts work together for a smooth function of the whole system

\section{FUTURE SCOPE}

To implement this project for domestic household purpose. To implement live tracking of each garbage truck. To implement plenty system on garbage collector for not doing the work properly. To implement the system using solar panel for power generation for our system. This step also greatly supports the use of renewable energy.

\section{REFERENCES}

[1] Malapur, B. S., \& Pattanshetti, V. R.(2017). "IoT BASED WASTE MANAGEMENT: AN APPLICATION TO SMART CITY". 2017 INTERNATIONAL CONFERENCE ON ENERGY, COMMUNiCATION, DATa ANALYTICS AND SOFt COMPUTING (ICECDS).

[2] Rohit, G. S., Chandra, M. B., Saha, S., \& Das, D. (2018). "SMART DuAl Dustbin Model for Waste MANAGEMENT IN SMART CitIES". 2018 3RD INTERNATIONAL CONFERENCE FOR CONVERGENCE IN TECHNOLOGY (I2CT). DOI:10.1109/I2CT.2018.8529600
[3] Tripathi, A., Pandey, C., Narwal, A., \& Negi, D. (2018). "Cloud Based SMARt Dustbin System for Metro StATION". 2018 3RD InTERNATIONAL CONFERENCE ON INTERNET OF THINGS: SMART INNOVATION AND USAGES (IOT-SIU). DOI:10.1109/IOT-SIU.2018.8519845

[4] Singhvi, R. K., Lohar, R. L., Kumar, A., Sharma, R., Sharma, L. D., \& Saraswat, R. K. (2019). "IoT Based SMART WASTE MANAGEMENT SYSTEM: INDiA PROSPECTIVE". 2019 4TH INTERNATIONAL CONFERENCE ON INTERNET OF THINGS: SMART INNOVATION AND USAGES (IOT-SIU). DOI:10.1109/IOT-SIU.2019.8777698

[5]HTTPS://WWW.RESEARCHGATE.NET/PUBLICATION/332574 816_IOT_BASED_SMART_TRASH_BINS_A_STEP_TOWARD_ SMART_CITY

[6]HTTP://WIKI.SEEEDSTUDIO.COM/GROVE-GAS_SENSORMQ2/

[7]HTTPS://WWW.KEYENCE.COM/SS/PRODUCTS/SENSOR/SENS ORBASIS/

[8]HTTPS://WWW.ELPROCUS.COM/INFRARED-IR-SENSORCIRCUIT-AND-WORKING/

[9]HTTPS://CREATE.ARDUINO.CC/PROJECTHUB/ONIICHAN_IS_ DED/LCD-I2C-TUTORIAL-664E5Al 